Original Article

\title{
Validation of smoothness evaluation during standing and sitting motions using an accelerometer
}

\author{
TAKeShi Shimamura, RPT ${ }^{1)^{*}}$, Hiroshi KatOH, RPT ${ }^{2)}$ \\ 1) Department of Rehabilitation, Kumamoto Kenhoku Hospital: 550 Tamana, Tamana-shi, Kumamoto \\ 865-0005, Japan \\ 2) Graduate School, Yamagata Prefectural University of Health Sciences, Japan
}

\begin{abstract}
Purpose] To quantitatively evaluate smoothness during standing and sitting motion analysis using an accelerometer and to clarify the relationship between indices. [Participants and Methods] Seventeen healthy males participated in this study. We attached a 9-axis motion sensor to the spinous process of the third lumbar spine and measured the acceleration of standing and sitting motions under normal and unstable conditions. We estimated and compared the root mean square and entropy in the lateral, vertical, longitudinal, and triaxial composite directions. [Results] On comparing both conditions, the unstable condition indices were significantly high, except for the lateral direction of entropy. The root mean square was significantly negatively correlated with entropy under normal conditions. [Conclusion] The study results suggested that the acceleration index quantitatively evaluates motion smoothness. Since each index had different characteristics, the motion-specific index was observed to be significant.

Key words: Accelerometer, Standing and sitting motions, Smoothness
\end{abstract}

(This article was submitted Oct. 15, 2020, and was accepted Dec. 7, 2020)

\section{INTRODUCTION}

Motion analysis in clinical settings is a highly specialized and essential part of physical therapy evaluation. In recent years, several studies using kinematic, kinetic and physiological indicators have been reported, benefiting from technological advances in electromyography, three-dimensional motion analysis devices, and accelerometer ${ }^{1-3)}$. Particularly, analysis using an accelerometer is a simple clinical evaluation tool because it is easy to wear and without restrictions on the measurement location. In addition, novel studies were also conducted from a qualitative perspective, focusing on the smoothness in the upper limb activity and walking ${ }^{4-6)}$. Previous studies have reported that the chair stand test time is related to the activities of daily living deterioration; however, only few studies have quantified smoothness in standing and sitting motions ${ }^{7}$. Evaluation and comparison between quantitative and qualitative perspectives during standing and sitting motions are useful. The root mean square (RMS) and entropy are typically reported smoothness measures. The RMS is a quantitative evaluation based on the magnitude of change over time ${ }^{8}$, and entropy is normalized after the frequency analysis and evaluated qualitatively as the probability curve ${ }^{4,9)}$, both measured using accelerometer only. No studies examined the relationship between the smoothness indices of standing and sitting motions, according to our studies. Therefore, this study aimed to investigate whether the RMS and entropy are used for the quantitative evaluation of smoothness during standing and sitting motions and to compare the usefulness of these indices in the clinical setting.

*Corresponding author. Takeshi Shimamura (E-mail: shimamura.t34@gmail.com)

(C2021 The Society of Physical Therapy Science. Published by IPEC Inc.

(c) (1) $\odot$ This is an open-access article distributed under the terms of the Creative Commons Attribution Non-Commercial No DerivaCC. ${ }_{\text {BY }}$ ND tives (by-nc-nd) License. (CC-BY-NC-ND 4.0: https://creativecommons.org/licenses/by-nc-nd/4.0/) 


\section{PARTICIPANTS AND METHODS}

Participants were 17 healthy males (age, $20.5 \pm 0.5$ years; height, $170.1 \pm 5.1 \mathrm{~cm}$; weight, $63.7 \pm 8.7 \mathrm{~kg}$; body mass index, $21.9 \pm 2.9 \mathrm{~kg} / \mathrm{m}^{2}$; mean \pm standard deviation [SD]) without previous orthopedic or neurological diseases. This study was conducted with the approval from the Ethics Committee of Kyushu University of Nursing and Social Welfare (26-020). In addition, all participants were informed on the purpose of the research and provided consent before participation.

A 9-axis wireless motion sensor (Motion Sensor) (Logical Products Inc., Fukuoka, Japan) was used to measure the acceleration data and was attached to participant's third lumbar spinous process (L3) using an elastic band, following the Moe Nilsen's method ${ }^{10)}$. The sampling frequency was set to $100 \mathrm{~Hz}$. The seating height was set at the height of the participant's knee fossa $(43 \pm 0.48 \mathrm{~cm})$ using a seated-height meter during standing and sitting motions. Standing and sitting motions were measured 8 times each using a metronome for 2 seconds each. The start and end of standing and sitting motions were defined as from sitting to full extension of trunk and both knee joints and until the return to sitting. We measured the motion under two conditions: an ordinary floor and an air cushion (Dynair ${ }^{\circledR}$ Ballkissen ${ }^{\circledR}$ XL; TOGU ${ }^{\circledR}$ GmbH, Bayern, Germany) (Fig. 1). The diameter of air cushion was $36 \mathrm{~cm}$, thickness was $7 \mathrm{~cm}$, max load was $200 \mathrm{~kg}$, and air pressure was $0.167 \mathrm{kPa} / \mathrm{kg}$, and sufficiently practiced the motions before the measurement. Approximately 5 times of motions were analyzed (20.48 s), excluding the first two and the last one. The tilt was corrected using the angular data obtained by integrating the angular velocity data of the frontal axis from the Motion Sensor. The RMS and entropy of the lateral, vertical, longitudinal, and composite triaxial directions of the analyzed data were estimated and compared. The triaxial composite was estimated from the square root of the sum of the squares of the lateral, vertical, and longitudinal components. The entropy was calculated using a fast Fourier transform with a Hanning window function and estimated from the normalized time series spectrum after excluding the first component.

Statistical analyses were performed using the IBM SPSS Statistics software version 23 (IBM Inc., Japan) to compare normal and unstable conditions and to examine the correlation coefficient between RMS and entropy. The Shapiro-Wilk test for normality and the Levene test for equal variability were used to examine normality, and two-sample t-test and MannWhitney's U-test were used to examine between groups. The Shapiro-Wilk test for normality of each indices, and Pearson's product-rate correlation coefficient ( $r$ ) and Spearman's rank correlation coefficient $(\rho)$ were used to examine the correlation coefficients. P-values of $<0.05$ were considered statistically significant.

\section{RESULTS}

The comparison between the normal and unstable conditions was shown using the RMS and entropy in the lateral, vertical, longitudinal, and triaxial composite directions during standing and sitting motions (Table 1). A typical example of normalized probability curves for entropy calculation of standing and sitting motions was shown, with normalized power on the vertical line and frequency (Hz) on the horizontal line (Fig. 2). The RMS was significantly higher under the unstable condition in the lateral, vertical, longitudinal, and triaxial composite directions. The entropy was significantly higher under the unstable condition, except in the lateral direction.

The relationship between indices between normal and unstable conditions is shown (Table 2). RMS and entropy comparisons under the normal condition were significantly negatively correlated in the lateral, vertical, longitudinal, and triaxial composite directions.

\section{DISCUSSION}

The unstable condition in the RMS was significantly higher during standing and sitting motions. We suggested that a higher value indicates less smoothness during standing and sitting motions.

The entropy was significantly higher in the vertical, longitudinal, and triaxial composite directions, although no significant difference was observed in the lateral direction. However, these are not necessarily periodic, and changes are smaller than those in vertical and longitudinal directions, the characteristics of standing and sitting motions. In addition, entropy differs from RMS in that its maximum value is uniquely determined according to the number of elements ${ }^{9)}$. Therefore, there is a possibility that no significant difference was observed between the two, even if the motion is not smooth. Values are high under unstable conditions; thus, the number of elements should considered when comparing them.

The relationship between RMS and entropy was significantly negative during standing and sitting motions under normal conditions, although both are reported as indicators of smoothness. There was a negative correlation trend during standing and sitting motions under unstable conditions, but were not significant. The RMS is an indication of how far off the average one is from the average. In other words, a large change in acceleration indicates a deviation from the steady motion and a large wobble. The entropy shows movement instability from the frequency band bias in the frequency analysis. Therefore, the RMS is a valid index for an extremely reliable repetitive and steady movements such as walking, although this index is probably not valid for repetitive standing and sitting motions with low periodicity.

The RMS evaluates whether the motion is out of average, and entropy evaluates the individual's periodic characteristics. Thus, the smoothness characteristics using various indices were examined according to the movement. In this study, we have 


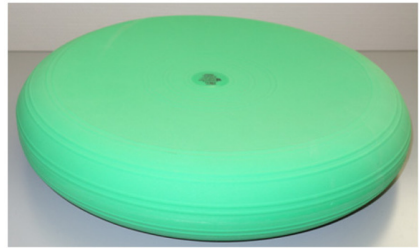

Fig. 1. Air cushion $\left(\right.$ Dynair $^{\circledR}$ Ballkissen $\left.^{\circledR} \mathrm{XL} ; \mathrm{TOGU}^{\circledR}\right)$.

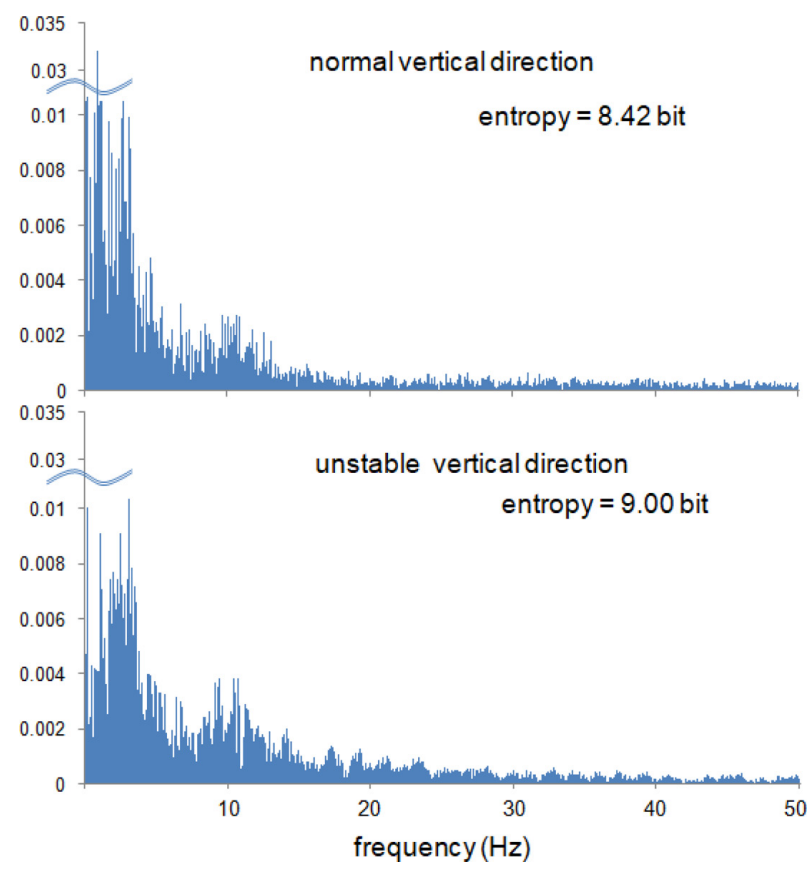

Fig. 2. Typical example of normalized probability curves for entropy.
Table 1. Comparison of normal and unstable conditions

\begin{tabular}{lllll}
\hline & & Normal & Unstable & \\
\hline RMS $\left(\mathrm{m} / \mathrm{s}^{2}\right)$ & Lateral & $0.05 \pm 0.03$ & $0.11 \pm 0.03$ & $* *$ \\
& Vertical & $0.10 \pm 0.02$ & $0.15 \pm 0.03$ & $* *$ \\
& Longitudinal & $0.10 \pm 0.02$ & $0.13 \pm 0.02$ & $* *$ \\
& Triaxial & $0.15 \pm 0.03$ & $0.23 \pm 0.04$ & $* *$ \\
Entropy (bit) & Lateral & $8.86 \pm 0.31$ & $8.79 \pm 0.19$ & \\
& Vertical & $8.47 \pm 0.25$ & $8.72 \pm 0.19$ & $* *$ \\
& Longitudinal & $8.62 \pm 0.17$ & $8.81 \pm 0.14$ & $* *$ \\
& Triaxial & $8.61 \pm 0.21$ & $8.77 \pm 0.18$ & $*$ \\
\hline
\end{tabular}

Mean \pm standard deviation. RMS: root mean square.

${ }^{*} \mathrm{p}<0.05,{ }^{* *} \mathrm{p}<0.01$ normal vs. unstable (RMS, entropy).

Table 2. Relationship between RMS and entropy indices

\begin{tabular}{llll}
\hline & & $\begin{array}{l}\text { Correlation } \\
\text { coefficient }\end{array}$ \\
\hline Normal & Lateral & $\rho=-0.82$ & $* *$ \\
& Vertical & $\mathrm{r}=-0.76$ & $* *$ \\
& Longitudinal & $\mathrm{r}=-0.78$ & $* *$ \\
& Triaxial & $\mathrm{r}=-0.70$ & $* *$ \\
Unstable & Lateral & $\mathrm{r}=-0.48$ & \\
& Vertical & $\mathrm{r}=-0.34$ & \\
& Longitudinal & $\mathrm{r}=-0.01$ & \\
& Triaxial & $\mathrm{r}=-0.14$ & \\
\hline
\end{tabular}

$* * \mathrm{p}<0.01$.

demonstrated that consideration of motion-specific indices is significant.

The limitations of this study are that the participants were healthy and under intentionally unstable conditions. Moreover, there is a necessity for future comparative studies on cases.

\section{Conflict of interest}

None.

\section{REFERENCES}

1) Bhardwaj S, Khan AA, Muzammil M: Lower limb rehabilitation using multimodal measurement of sit-to-stand and stand-to-sit task. Disabil Rehabil Assist Technol, 2019, 10: 1-8. [Medline] [CrossRef]

2) Carpino G, Tran S, Currie S, et al.: Does manual therapy affect functional and biomechanical outcomes of a sit-to-stand task in a population with low back pain? A preliminary analysis. Chiropr Man Therap, 2020, 28: 5. [Medline] [CrossRef]

3) Abe D, Hotta N, Fukuoka Y, et al.: Biomechanical analysis of gait and sit-to-stand patterns using a specially made knee supporter in healthy young and elderly individuals. J Physiol Anthropol, 2010, 29: 65-70. [Medline] [CrossRef]

4) Kojima M, Obuchi S, Mizuno K, et al.: Power spectrum entropy of acceleration time-series during movement as an indicator of smoothness of movement. J Physiol Anthropol, 2008, 27: 193-200. [Medline] [CrossRef]

5) Kavanagh JJ: Lower trunk motion and speed-dependence during walking. J Neuroeng Rehabil, 2009, 6: 9. [Medline] [CrossRef]

6) Kojima M, Obuchi S, Henmi O, et al.: Comparison of smoothness during gait between community dwelling elderly fallers and non-fallers using power spectrum entropy of acceleration time-series. J Phys Ther Sci, 2008, 20: 243-248. [CrossRef] 
7) Wang DX, Yao J, Zirek Y, et al.: Muscle mass, strength, and physical performance predicting activities of daily living: a meta-analysis. J Cachexia Sarcopenia Muscle, 2020, 11: 3-25. [Medline] [CrossRef]

8) Menz HB, Lord SR, Fitzpatrick RC: Acceleration patterns of the head and pelvis when walking on level and irregular surfaces. Gait Posture, 2003, 18: 35-46. [Medline] [CrossRef]

9) Kojima M, Obuchi S: Evaluating the usefulness of power spectrum entropy of acceleration time-series in setting the load for high-intensity strength training for the frail elderly. Rigakuryoho Kagaku, 2012, 27: 291-296 (in Japanese). [CrossRef]

10) Moe-Nilssen R: Test-retest reliability of trunk accelerometry during standing and walking. Arch Phys Med Rehabil, 1998, 79: 1377-1385. [Medline] [CrossRef] 